\title{
Toward The Goal \\ Of Teaching Excellence In Accounting: Reexamining The Role Of Neutrality And Conservatism In The Development Of Pension Accounting Standards
}

Brian W. Carpenter, (E-mail: bwc352@uofs.edu,), The University of Scranton Daniel P. Mahoney, (E-mail: mahoneyd1@scranton.edu), The University of Scranton

\begin{abstract}
Pension accounting is replete with complexities that present difficulties to even the most seasoned accounting practitioners. It thus represents one of the more problematic areas of the accounting curriculum for accounting students and instructors alike. Traditional approaches toward the teaching of pension accounting rely heavily on memorization techniques that tend to serve students' needs on a short-term basis. The authors present an alternative approach to instruction in which students assume the role of accounting standard setters and seek to develop pension accounting rules that favor corporate interests. This approach allows students to recognize the economic consequences that standard setters sometimes consider in their promulgation of accounting and financial reporting rules. The result is that students acquire a greater depth and breadth of understanding of pension accounting rules and why those rules exist as they do. They also acquire a keener understanding of the broader standard setting process. This logic-based approach is likely to better serve the long-term needs of our future accounting professionals.
\end{abstract}

\section{Introduction}

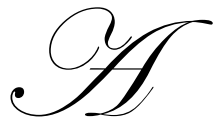

ccounting for pensions is one of the more important, and unfortunately, most problematic areas in financial accounting. For many major U.S. corporations, pension obligations represent, by far, their largest single liability - a fact that energizes any debate concerning attempts to alter these measures. Pension accounting is thus one of the most contentious issues currently facing the accounting profession, and even a cursory historical review of the standard setting process shows that the pension area has long been a source of great controversy. This contentiousness has resulted in perhaps the most complex set of reporting rules in the history of financial accounting and reporting. These long-standing inherent complexities of pension accounting create difficulty not just for accounting practitioners, but also for accounting academicians who strive to present the material in a logical and understandable format.

Adding to the difficulty of "teaching pension accounting" is the fact that many facets of pension accounting rules are incongruent with the underlying conceptual framework on which a meaningful and consistent body of generally accepted accounting principles is purportedly based. Strict adherence to the Financial Accounting Standard Board's (FASB's) Conceptual Framework would have resulted in a system of pension accounting that would have been markedly different from that which is required under current accounting standards. The FASB 's departure was necessary in order to stave off significant economic consequences that would have resulted from the use of the more accurate actuariallybased measures of pension liabilities. 
And while one could possibly criticize the FASB for its consideration of "economic consequences" when promulgating these standards, it is this very point that provides accounting academicians with a unique instructional opportunity. The FASB's departure from the much-discussed conceptual framework can actually be used to provide students with a more intuitive and logical understanding of our current pension standards. We believe that in order to effectively understand the accounting regulations for defined pension benefit plans, students must consider the bases on which various decisions were made during the promulgation of the standards. More specifically, students actually need to adopt a mindset (a role-playing, of sorts) that favors corporate interests in order that they might understand the decisions made by the FASB in creating the relevant pension standards. Such a mindset helps facilitate their understanding of the resulting measures of pension liability and expense that make their way into the main body of the financial statements.

This paper proposes a method of teaching pension accounting that offers students not just an understanding of the currently effective pension accounting rules, but also a keener insight into the overall standard setting process. A better understanding of the underlying motives enhances student understanding of the specific pension accounting requirements. This "logic-based" approach would seem to offer greater long-term comprehension than is offered via the more traditional "learn these rules" approach. Additionally, by approaching these standards from this perspective, students stand to gain a better appreciation of the pressures that the FASB faces during the standard-setting process and a better understanding of how its decisions ultimately impact the economy.

\section{The Pension Accounting Controversy}

The accounting profession has long recognized the need to improve the regulations for pension accounting, particularly with respect to defined benefit pension plans. However, the profession has for various reasons taken an incremental approach to this problem. The main obstacle to a more immediate and comprehensive solution to pension reporting deficiencies has been the well-grounded fear of the economic consequences of such a move. For many years, pension obligations were not recorded as they accrued, but were instead recorded when paid. Of course, this approach constituted a major violation of the tenets of accrual basis accounting. While it was obvious that such an approach was conceptually inappropriate, the economic and political consequences of any contemplated move to the more appropriate full accrual of pension costs were too significant to ignore. The profession thus took an incremental approach wherein each subsequent pension regulation sought to incrementally improve, rather than solve, the reporting of defined benefit pension measures. They accomplished this primarily through comprehensive footnote disclosure and the gradual inclusion of additional amounts of previously unreported net obligation in the main body of the financial statements.

The execution of this incremental approach required new and frequently novel methods of measuring a firm's pension obligation. One outcome of this approach is that the full measures of pension obligations and related assets are not directly reported in the main body of the financial statements. Most of the measures of the financial consequences of defined benefit pension plans, including the more accurate measures of the overall pension obligation and associated assets, are instead accounted for in accounts that are kept "off the books." Those measures that do in fact make their way onto the main body of the financial statements are, in effect, artifacts that result only after the more accurate "offthe-books" measures go through a myriad of various complex mathematical manipulations.

Before proceeding with further discussion of these complex pension measures, one might logically ask how it is that pension accounting requirements have evolved to their current state. To answer this question, it is most helpful to momentarily digress into an historical look at the development of pension accounting standards.

\section{History of Defined Benefit Pension Accounting}

Official pension reporting standards date back to 1948, when the Committee on Accounting Procedure issued Accounting Research Bulletin (ARB) No. 36, "Accounting for Annuity Costs Based on Past Services". Prior to ARB 36, pension accounting and reporting took a purely cash basis approach. In contrast, ARB 36 recommended that companies allocate their respective unfunded accumulated benefits over current and future periods, thus matching the "startup" costs of pension plans against future revenues resulting from the labor provided by employees. ARB 36 
further indicated that the costs of benefits based on prior employee service should not be charged to retained earnings (then referred to as "earned surplus") - a position on which the Committee on Accounting Procedure would later reverse itself when deliberating on the issue of pension liabilities and their recognition on the balance sheet.

It was in 1956, through its issuance of ARB 47, "Accounting for Costs of Pension Plans," that the Committee on Accounting Procedure formally acted on the concept of liability recognition. This standard recommended that unfunded vested benefits be reported on the face of the balance sheet - a bold concept even for its time. ARB 47 also took the stance that companies that already had pension plans in place should charge the entire amount of prior service cost to retained earnings. Furthermore, this research bulletin set forth the notion that adoption of/changes to a pension plan should be disclosed in the notes to the financial statements. While ARB 36 had rejected the notion of taking a onetime charge against retained earnings, ARB 47 indicated that it may in fact be appropriate for companies that had not adequately accounted for prior service costs to take such a one-time charge. Although this positional change may be slight, it reinforces the idea that cohesive rules regarding pension accounting have long been in a state of continual evolution.

With the formation of the Accounting Principles Board (APB) in 1959, there came the prospect of increased uniformity and consistency in various areas of financial reporting, including that of pension reporting. In 1966, the APB issued APB Opinion No. 8, "Accounting for the Costs of Pension Plans." The primary focus of APBO No. 8 was the measurement of periodic pension expense, and this measure was determinable using any of a number of acceptable actuarial cost methods, irrespective of the employer's cash contributions (a fact that underscores the move from cash basis to accrual basis accounting). APBO No. 8 was viewed as a significant step toward the goal of standardized pension accounting, and it was considered noteworthy that its requirements were premised on the findings of a formal (Hicks, 1965) research study. Nonetheless, this new standard quickly became the focus of criticism - largely because of the lack of uniformity that resulted from the array of allowable actuarial cost methods.

Criticisms of APBO No. 8 also focused on the standard's failure to require recognition of a liability for past and prior service cost. It was argued that failure to require recognition of such a potentially significant obligation could easily result in a material distortion of the firm's reported financial position (a point that reflects an obvious manifestation of the economic consequences argument that prevails even to today). The controversial aspects of pension accounting and reporting thus continued to abound, and it was clear to many that the evolution of pension accounting standards was far from complete. APB No. 8 was subsequently amended by the Accounting Principle Board's successor, the Financial Accounting Standards Board (FASB), when the latter issued Statement of Financial Accounting Standards No. 36, "Disclosure of Pension Information" in 1980. This standard addressed only the disclosure (as opposed to measurement) issues pertaining to pension plans, and critics continued to cite the variation that existed in inter-company and inter-temporal pension expense.

In December 1985, the FASB issued Statement of Financial Accounting Standards No. 87, "Employers' Accounting for Pensions". Statement 87 marked the culmination of a lengthy effort to bring uniformity and comparability to pension reporting. One of the significant changes imposed by Statement 87 was that of the standardized method for measuring net periodic pension cost - a move that was clearly intended to improve comparability and understandability. Another significant change was the required immediate recognition of a liability known as the "minimum pension liability" when the accumulated benefit obligation exceeds the fair value of plan assets. The FASB viewed this latter requirement as a means of limiting the extent to which the delayed recognition of plan amendments and losses in net periodic pension cost can result in omission of certain liabilities from balance sheets.

Statement 87 was thus viewed - at least by the FASB - as a significant step forward in the development of a rational and systematic means of accounting for defined benefit pension plans. Interestingly, however, even the FASB was quick to note that this new standard was not to be regarded as the final chapter in the pension accounting saga:

This statement continues the evolutionary search for more meaningful and more useful pension accounting. The FASB believes that the conclusions it has reached are a worthwhile and significant step in that direction, but it also believes that those conclusions are not likely to be the final step in the evolution. Pension accounting in 1985 is still in a 
transitional stage. (para no. 5 of SFAS No. 87)

Arthur Wyatt, a member of the FASB at that time, underscored the incremental nature of SFAS No. 87 and the need for future progress in this area by stating that "...this Statement falls short of achieving the degree of improvement in accounting for pension costs that was attainable and that users of financial statements could justifiably expect from this project.” (page 27, SFAS No. 87). The concluding paragraphs of SFAS No. 87 reiterated his position by noting that:

Mr. Wyatt agrees with the assenters that, on an overall basis, the conclusions in this Statement will lead to improvements in accounting for an understanding of pension costs. He believes, however, that the degree of improvements is modest when related to the improvement that he believes should have been achieved. Thus in his view the Statement's deficiencies represent a lost opportunity for improvement in financial reporting (page 28)

The requirements of SFAS No. 87 can thus be viewed as an additional step in an incremental approach toward measurement and accrual of pension expenses and liabilities. As was previously noted in paragraph five of the Standard, the FASB itself openly considered the standard to be only a step in what they viewed as a longer term evolution. However, there has been very little change in these accounting standards outside of the area of increased disclosure. The components of pension expense and liability that are reported within the main body of the financial statements themselves are still nearly identical to what was required by the so-called evolutionary step taken nearly 20 years ago. The deficiencies in these standards are betrayed by the need for a "minimum pension liability". The need for a minimum pension liability underscores the fact that the current measures of pension liabilities and expenses still fail to fully reflect the actuarial and market based measures that more faithfully represent the true valuations of these obligations. Instead, the transitional "off-the-books" approach of pension reporting still prevails, even though this approach was long ago considered only "a step in the evolution" of an area of accounting that was in a "transitional stage".

Interestingly, the goal of improving these reporting requirements through a process of evolutionary change was re-expressed by a subsequent FASB when it developed SFAS No. 106. Statement No. 106 addresses employers' accounting for postretirement benefits. The issues involved in accounting for postretirement benefits are very similar to the issues involved in accounting for defined benefit pension plans. Ultimately, the accounting techniques and requirements adopted by SFAS No. 106 for postretirement benefits largely mirrored those previously established for defined benefit pensions as by SFAS No. 87. However, the part of SFAS 106 most relevant to our current discussion was its reiteration of the need for incremental progress in what was considered an evolutionary process. In fact, this position was emphasized by having separate sections of the standard specifically entitled "Evolutionary Changes in Accounting Principles" (see paragraphs 140-141) and "Improvements in Financial Reporting" (see paragraphs 142-145).

What were simply dissenting comments in SFAS No. 87 had now grown in importance and significance such that the notion of "evolutionary" change was now overtly part of the latter standard's text. The most relevant part of these references was the apparent need to rationalize and explain what must have been perceived as the slow pace of change in this evolutionary process. Paragraph 140 of SFAS No. 106 offered this explanation by stating "Paragraph 2 of FASB Concepts Statement No. 5, Recognition and Measurement in Financial Statements of Business Enterprises, states that 'the Board intends future change to occur in the gradual, evolutionary way that has characterized past change.' The Board realizes that the evolutionary change may have to be slower in some areas than in others" (para 140, SFAS 106). Apparently, the members of that Board believed that the change that had taken place in this area of accounting during the five years since the passage of SFAS No. 87 was small enough to merit an overt statement that justified the slow progress. One could only imagine what those members of FASB would have thought if they could have known that their reporting requirements would still be largely unchanged fifteen years later.

\section{The FASB's Rationale}

The main reasons for the development of this complex off-the-books approach were to: 1) avoid negative economic consequences that would arise from a sudden switch to accrual based measures, and 2) smooth the volatility that would accompany the use of the more accurate market-based values of pension assets. While the problems 
associated with the latter of these two reasons are currently the topic of much press and discussion, both of these goals contradict the more commonly referenced objectives, such as neutrality and representational faithfulness, that are typically used to guide the accounting standard setting process. And while the FASB has initiated a project that will address some of the problems associated with pensions, it is highly unlikely that the current Board will propose any solution that will result in true accrual based measures of pensions that are directly reported within the main body of the associated financial statements. Instead, it is more likely that the FASB will continue the profession's longstanding incremental approach to this problem, and will attempt to address the associated flaws of the current system via enhanced disclosure.

The root cause of the current deficiencies in accounting for defined benefit pensions is based on the failure to fully employ accrual accounting. Ironically, the use of accrual accounting would be far easier to accomplish and understand than the current complex system. As has historically been the case, the main reason for not using the actuarial and market-based measures is the desire to avoid negative economic consequences that would likely accompany the use of these more accurate, yet more volatile, measures of defined benefit pension plans. While the profession may have valid reasons for smoothing the financial impact of the volatility of defined benefit pension plans, it remains that the resultant pension accounting standards violate several basic tenets of accounting.

The execution of this incremental approach required a new way of measuring and reporting defined benefit pension obligations. From a teacher's perspective, the most relevant aspect of this approach is that it requires defined benefit pensions accounts to be largely accounted for "off the books". One of the more noteworthy outcomes of this approach is that the most accurate measures of defined benefit pension obligations and assets are not directly reported in the main body of the financial statements. These actuarially and market based measures of the pension obligations and assets are disclosed in the notes to the financial statements, but are not reported in the main body of the company's financial statements. The measures that do in fact make their way onto the main body of the financial statements are, in effect, artifacts that result only after the more accurate 'off-the-books' measures go through a myriad of various complex mathematical manipulations.

\section{The Continuing Controversy - A Useful Teaching Pedagogy}

These various issues pertaining to the topic of accounting for defined benefit pension plans provide accounting professors with a uniquely powerful illustration of how economic considerations can indeed affect the accounting standard setting process. Typical accounting lectures make reference to the conceptual framework in which accounting standards are purportedly grounded. The pension accounting topic, however, reveals the fact that departures from the concepts standards are sometimes made in order to mitigate what are perceived as undesirable economic consequences. In the case of pensions, for example, standard setters saw a need to depart from the principle of neutrality in order to avoid the sudden inclusion of large and potentially volatile amounts of unfunded pension obligations that would have negatively affected reported corporate financial performance, and thus, arguably the economy itself. It is this departure from the much-discussed conceptual framework that provides accounting faculty with a unique instructional opportunity and a means of providing their students with a more accurate insight into the standard-setting process.

It is our contention that the teaching of accounting is frequently enhanced by the ready admission that the standard setting process sometimes considers economic considerations. We believe that such a perspective provides a more logical - and perhaps more truthful - method of teaching certain accounting standards. This approach seems particularly effective for the teaching of pensions. An exposure to the controversial history of pension accounting sensitizes students to the unique compromises that were made in this area of accounting regulation. From this perspective, it is easier to explain to students why the profession chose to account for most components of defined benefit pensions "off the books" and why this particular standard may violate norms usually associated with the ideals expressed in the conceptual framework. From this base, we then ask our students to examine the individual decisions that were considered during the development of the accounting standards for defined benefit pensions. We believe that this approach provides a more interesting and effective basis for discussion with respect to the entire standard-setting process. 
It is also our contention that most of the FASB's pension accounting decisions become logical and intuitive only if it is presumed that the rules were developed by a board that was sympathetic to corporate interests. Accordingly, our teaching approach requires students to assume the same perspective. This perspective allows us to abandon the traditional memorization and "fill-in-the-blanks" approaches to pensions that are frequently taken in Intermediate Accounting texts. The more salient issues that we believe are enhanced through this proposed pedagogical approach to the teaching of pension accounting include:

- $\quad$ pension liabilities that escape the balance sheet;

- $\quad$ accounting procedures that lessen the reported pension expense;

- $\quad$ aspects of pension standards that lessen the reported net pension obligation.

\section{Application of the Role-Playing Pedagogy}

Students of accounting are exposed to many concepts that suggest a forthcoming approach to financial reporting. Issues such as "conservatism" and "full disclosure" can easily lead one to believe that the financial reporting process is one of straightforward measurement and complete revelation of a company's costs and obligations. However, careful study of the pension accounting standards betrays the fact that financial reporting sometimes masks a company's overall financial position and does so in ways that favor corporate interests. With regard to a company's reported pension obligation, for example, the pension standards prescribe the use of the accumulated benefit obligation (ABO) when a smaller measure of the obligation is beneficial to the corporation, and prescribe the use of the projected benefit obligation (PBO) when a larger measure of the obligation is more beneficial. More specifically, the ABO is used in determining the amount of any "minimum pension liability" to be reported, and thus minimizes the reported amount of any such liability. In contrast, the PBO is used as one of the two possible determinants of the "corridor amount", and is thus less likely than a smaller measure of the pension obligation (e.g., the $\mathrm{ABO}$ ) to trigger the amortization process that could potentially force recognition of previously deferred liabilities and expenses.

By asking students to place themselves in the role of the accounting standard setters, and encouraging them to take a position that favors corporate interests, the students will likely find that they make key decisions in their simulated standard setting process that closely mirror those decisions taken by the actual members of FASB. This approach fosters a more intuitive and keener understanding of pension accounting standards than is typically possible via a memorization-based approach. This pedagogy also promotes a superior understanding of the standard setting process - an understanding that would arguably serve them well in their study of other (i.e., non-pension) accounting standards.

This pedagogy provides a similarly useful basis for fostering a more intuitive student understanding of the expense-related provisions of the pension accounting standards. Once accounting students have completed the introductory sequence of accounting courses, they clearly understand that companies not only seek to maximize reported profitability, but also to minimize, where possible, the period-to-period volatility of their earnings. By instructing students to take a position that favors corporate interests, they naturally develop a pension standard that minimizes the reporting of pension-related expenses, obligations, and associated market volatility. Indeed, this same position is reflected in SFAS No. 87. More specifically, even when the provisions of Statement 87's "minimum pension liability" apply and an additional liability must therefore be reported, the corresponding "debit" is frequently to an asset account - rather than an expense account - thus once again favoring corporate interests. And in those circumstances wherein no rationale can plausibly be given for assigning this debit to an asset, the debit is made to a contra-equity account -- a practice that again avoids any immediate recognition of an expense. Such treatment clearly contradicts many of the principles and objectives that students expect to serve as the basis for the accounting standard setting process. Thus, once again, students develop a more intuitive understanding of the current pension standards by replacing the traditional foundation for understanding the provisions of financial accounting with a perspective that is sympathetic to corporate interests. 
The traditional "memorize these requirements" approach to the study of pension accounting understandably leaves students with an element of confusion, especially those students who attempt to find the linkage to the FASB's Conceptual Framework. In contrast, the role-playing approach leaves students with a much clearer understanding of the pension accounting requirements, the motives underlying those requirements, and the standard-setting process in general. It also heightens their sensitivity to the meaning of neutrality as it pertains to the standard setting process, and the frequently inherent conflict between societal expectations and corporate desires.

The benefits of our suggested role playing perspective extend to even the more seemingly esoteric areas of pension accounting, such as the use of market-related values (MRV) rather than fair market values as one of the two possible determinants of the "corridor amount" provision of Statement No. 87. The use of market-related values has a smoothing effect on reported income. Given that firms seek to avoid volatility of reported income measures, a perspective that is sympathetic to corporate ideals once again provides the intuitive basis for understanding specific provisions of the pension standards. Thus, students escape the need for large amounts of memorization and are able to avoid the inherent frustration that they would otherwise experience from the many unexplained inconsistencies between the existing regulations and the ideals expressed in the Conceptual Framework.

\section{Conclusion}

Our proposed approach to the teaching of pension accounting departs from the more traditional textbook approach. Our students are asked to consider what they would do if they were members of the FASB - with the extra provision that they also adopt stances that are sympathetic to corporate interests. By thinking from this perspective, students obtain a keener insight into the standard setting process as well as a more detailed understanding of the motives that underlie the pension accounting requirements. Thus, rather than a teaching style that promotes "memorizing the rules," this approach provides students with a deeper understanding as to why the rules exist as they do. Such an understanding will presumably serve them well throughout their professional careers.

\section{References}

1. Committee of Accounting Procedures, "Pension Plans - Accounting for Annuity Costs Based on Past Services," Accounting Research Bulletin No. 36 (American Institute of Accountants, 1948)

2. Committee of Accounting Procedures, "Accounting for Costs of Pension Plans," Accounting Research Bulletin No. 47_(American Institute of Accountants, 1956)

3. Accounting Principles Board, "Accounting for the Cost of Pension Plans," APB Opinion No. 8 (American Institute of Certified Public Accountants, 1966).

4. $\quad$ Financial Accounting Standards Board, "Objectives of Financial Reporting by Business Enterprises," Statement of_Financial Accounting Concepts No.1 (FASB, 1978).Financial Accounting Standards Board, "Qualitative Characteristics of Accounting Information," Statement of Financial Accounting Concepts No.2 (FASB, 1980).Financial Accounting Standards Board, "Elements of Financial Statements of Business Enterprises," Statement of Financial Accounting Concepts No.3 (FASB, 1980).Financial Accounting Standards Board, "Disclosure of Pension Information," Statement of Financial Accounting Standard No.36 (FASB, 1980).

8. Financial Accounting Standards Board, "Recognition and Measurement in Financial Statements of Business Enterprises," Statement of Financial Accounting Concepts No.5 (FASB, 1984).Financial Accounting Standards Board, "Employers' Accounting for Pensions," Statement of Financial Accounting Standard No.87 (FASB, 1985).

10. Financial Accounting Standards Board, "Employers' Accounting for Postretirement Benefits other than Pensions," Statement of Financial Accounting Standard No.106 (FASB, 1990).

11. Financial Accounting Standards Board, "Employers' Accounting for Postemployment Benefits—an amendment of FASB Statements No. 5 and 43," Statement of Financial Accounting Standard No.112 (FASB, 1992).

12. Financial Accounting Standards Board, "Employers' Disclosures about Pensions and Other Postretirement Benefits - an amendment of FASB Statements No. 87, 88, and 106," Statement of Financial Accounting 
Standard No.132 (FASB, 1998).

13. Hicks, Ernest L., Accounting Research Study No. 8, Accounting for the Costs of Pension Plans (American Institute of Certified Public Accountants, 1965).

Notes 